\title{
Study on the Training Mode of Interlanguage Pragmatic Competence of Minority Non-English Majors
}

\author{
Jing Yu \\ ABA Teachers University, Sichuan, 611730, China
}

\begin{abstract}
Keywords: Minority Colleges; Non-English Major; English Teaching; Tibet Tibetan Medical College
\end{abstract}

\begin{abstract}
This paper takes the English teaching status of non-English major undergraduate students in Tibet College of Tibetan Medicine as the research object, and analyzes the teaching status of students' students, teaching materials, teaching conditions and teacher strength. In order to achieve a better teaching effect, countermeasures and suggestions such as updating the teaching concept, implementing graded teaching, strengthening the preparation of self-made teaching materials, setting up diversified courses, and improving students' self-awareness are proposed.
\end{abstract}

\section{Introduction}

In recent years, Tibet's social and economic development has been rapid, and the increasing exchanges of foreign exchanges have placed higher demands on English education in Tibet. Tibet Tibetan Medical College is a national college that trains Tibetan medical professionals. The college students are non-English majors. English teaching has outstanding national characteristics. College English is a compulsory basic course for college students. It is of great significance to improve the level of English teaching in Tibetan medical schools.

\section{Status quo of teaching}

Tibet Tibetan Medical College has three departments: Department of Tibetan Medicine, Department of Tibetan Medicine, and Department of Continuing Education. All students study the College English course in the first year of the university, with 72 hours per semester [1].

\subsection{Student source}

The Tibetan College of Tibetan Medicine is mostly Tibetan, with a ratio of Tibetan to Chinese students of about 70:1. Tibetan students are mostly from remote areas, pastoral areas and mountainous areas, and the English foundation is generally weak. In the process of learning, Tibetan is the first language, Chinese is the second language, English is the third language, and the three languages belong to different languages. The difference is large, so the difficulty of English learning is relatively large.

\subsection{Teaching materials}

At present, the "University English" textbooks marketed and sold in the market are diverse and numerous, but the special English textbooks that specifically target the special needs of minority colleges and minority college students are still blank. The Tibetan Medical College of Tibet combined with the students' English learning in the school. After many investigations and expert opinions, the relevant teachers were organized to prepare English self-edited textbooks suitable for the undergraduate training needs of Tibet Medical College. In the teaching, the use of national textbooks and self-edited textbooks for the semester, the teaching effect is better, effectively improving the level of English teaching.

\subsection{Evaluation system}

The formative evaluation of English teaching in Tibet Tibetan Medical College consists of three 
parts: final exam scores + usual grades + mid-term exam scores. The final exam papers are uniformly formulated by the English proposition group, and their scores account for $70 \%$ of the scores of the subjects; the usual grades are composed of attendance, classroom performance, and usual assessments, accounting for $15 \%$, and the mid-term exams are various in form, accounting for $15 \%$.

\subsection{Teaching conditions}

In 2012, Tibet Tibetan Medical College gradually realized multimedia teaching. On the basis of traditional teaching, teachers can use multimedia PPT to show students more vivid and detailed information. In addition, it is also possible to cultivate students' English language habits by playing European and American movies and news suitable for teaching, to improve listening and speaking skills, and to mobilize students' interest in learning[2].Language teaching mode as shown below.

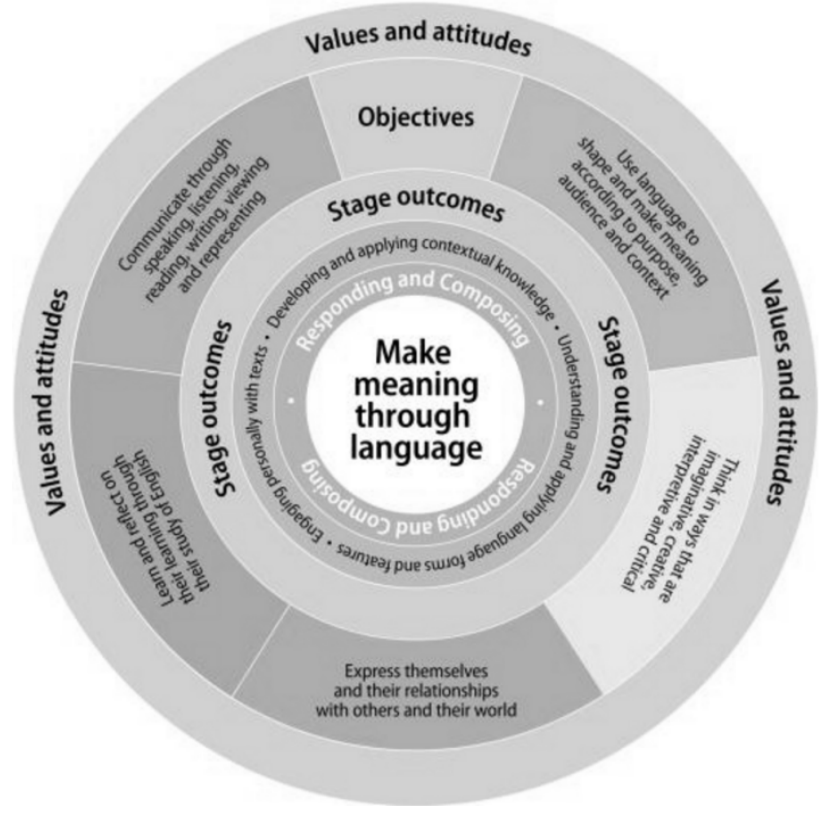

Fig.1 Language teaching mode

\section{Some problems}

\subsection{Insufficient faculty}

Tibet Tibetan Medical College currently has more than 1,600 students, but only nine English teachers. Each freshman in this special year has about 8 classes, and each class has 72 hours of instruction per semester, which is 4 hours per week. In addition to the postgraduate English teaching tasks, the faculty is seriously inadequate.

\subsection{Insufficient teacher training}

The existing training system in Tibet is based on basic education, and there is less training for college teachers. College teachers have certain advantages in professional, but there are great difficulties in the acquisition of academic frontier information and the cultivation of student assistants. The excessive class hours of college teachers also make it difficult for teachers to carry out after-school training work. There is still a long way to go in the training of college teachers[3].

\subsection{The academic exchange between teachers is not enough}

First, the number of teachers is small, the amount of classes is large, and many teachers are shoulder-to-shoulders, resulting in limited academic exchanges between teachers and poor results. Second, the school's teacher management system needs to be further improved, and the enthusiasm of teachers is constantly stimulated. 


\section{Countermeasures and recommendations}

Language has communicative and social nature, which makes English teaching different from other subjects, especially classroom teaching.

\subsection{Update the teaching concept}

The reform of English classroom teaching should first be to update the teaching concept. The English teaching mode of Tibet Tibetan Medical College is mainly a traditional, teacher-centered teaching mode. The disadvantage is that it ignores the cultivation of listening, translation, writing and speaking skills, resulting in an imbalance in the development of students' English skills, and the essence of practice is ignored. Teachers should carefully design classroom teaching links according to the characteristics and difficulties of non-English majors' English learning in minority colleges and universities, appropriately adjust teaching strategies with students as the center, improve evaluation methods, and actively guide students to learn independently. At the same time, give students a certain choice, arrange learning tasks according to their interests, and truly mobilize students' initiative, enthusiasm and creativity.

\subsection{Implement graded teaching}

Graded teaching can also be called hierarchical teaching. After the students enter the school, they will take the English grade examination, and then combine the students' wishes to divide the students into basic classes, intermediate classes and improvement classes. Clarify learning priorities, learning requirements and learning objectives at different levels, using different syllabuses, teaching materials, teaching content, teaching methods and assessment methods. For example, the basic classes of students focus on the basic knowledge, intermediate classes and improvement classes focus on the cultivation of practical skills. Graded teaching can not only meet the specific requirements of English learning at different levels, but also help to cultivate students' ability to apply English. Teachers can also teach students in accordance with their aptitude and aim at teaching activities [4].Language communication mode as shown below.

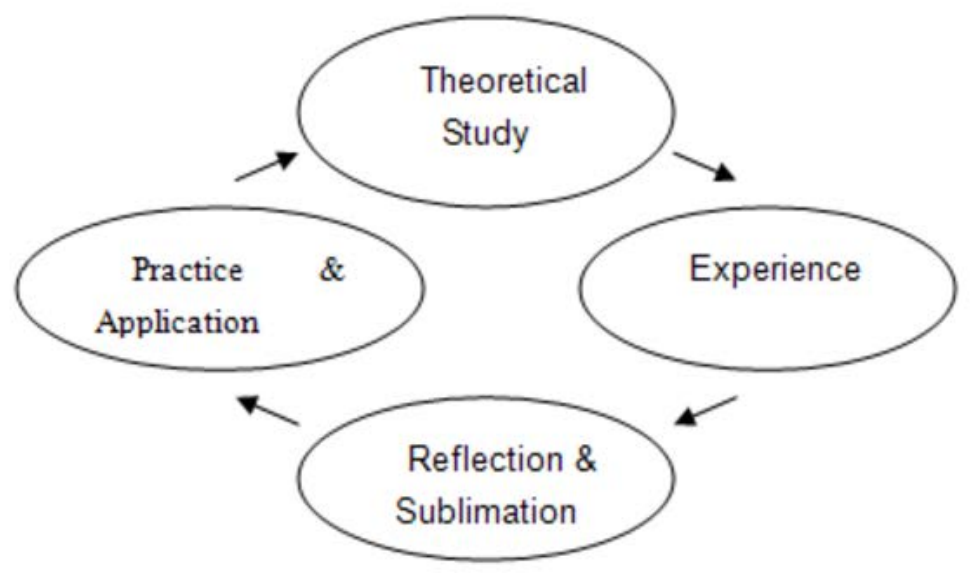

Fig.2 Language communication

\subsection{Strengthen the preparation of self-made teaching materials}

Graded teaching puts forward a higher level of requirements for the selection and use of textbooks. In view of the particularity of English teaching in Tibet Tibetan Medical College, the school has selected self-made teaching materials in the teaching process, which has effectively improved the level of English teaching. However, self-editing textbooks are not perfect. Teachers should delete boring and outdated articles in the teaching process, and provide timely feedback on the problems existing in the textbooks. The textbook writing group should organize the first-line teaching teachers to continuously modify the content of the textbooks, and encourage teachers to strengthen cooperation inside and outside the school, which will reflect the social and economic development of Tibet, the history and development prospects of Tibetan medicine and Tibetan medicine, natural landscape and folk customs are equal to Tibetan social culture. The content of life 
and the characteristics of the school is reflected in the textbooks, focusing on the knowledge, time and ideology of the article, enhancing students' interest in learning and national self-confidence and pride, and transforming them into positive factors in the process of English learning.

\subsection{Diversified curriculum}

In addition to strengthening the basic English curriculum in the process of English teaching, students can also combine professional courses with applied skills courses and language and culture courses. While ensuring students' basic skills such as listening, speaking and reading, they offer English elective courses with different contents, such as the combination of Tibetan traditional culture and English, reading of European and American newspapers and periodicals, and Tibetan medicine and related content. The diversity of curriculum settings can increase students' ways of learning English, enrich learning content, and help students develop their independent learning ability and comprehensive application ability.

\subsection{Improve students' self-learning ability}

To improve the comprehensive application ability of English in an all-round way, it is not enough to rely solely on classroom education. In addition to improving the quality of classroom education, it is also necessary to strengthen students' extracurricular self-directed learning. The Tibet College of Tibetan Medicine established the English Corner and organized an English speech contest, which played a positive role in promoting students' self-learning ability.

\section{Summary}

In the new media era, in addition to relying on the platform provided by the school, students can also set up study groups outside the classroom. Under the guidance of the teachers, students exchange and supervise each other, and select learning content according to their own level, which can effectively improve their autonomy.

\section{Acknowledgement}

Aba Prefecture special fund project for Social Science in 2016: Research on the Interlanguage Pragmatic Competence and Its Development Model for the Minority Non-English Majors (ABK004)

This work in the project, On the Interlanguage Pragmatic Competence of Tibetan EFL Learners Based on Compliment Responses, was supported by the Scientific Research Foundation of Aba Tea chers University in 2018(No: ASB18-23).

\section{References}

[1] Jian LI, Kunming YAO. On Connotative Development of Foreign Language Teaching in Chinese Universities [J]. Higher Education of Social Science, 2014, 6(2).

[2] Ugur Demiray. From Editor vol 11, No.3 [J]. The Turkish Online Journal of Distance Education, 2010, 11(3).

[3] John M. Norris. Language Program Evaluation [J]. The Modern Language Journal, 2016, 100(S1).

[4] Kuchma V R,Efimova N V, Tkachuk E A, Mylnikova I V. [Hygienic assessment of the overwroughtness of educational activity in schoolchildren of 5-10 classes of secondary schools].[J]. Gigiena i sanitariia, 2016, 95(6). 